\title{
POLÍTICAS CULTURALES Y ESTADO-NACIÓN: LAS DECLARACIONES DEL PATRIMONIO HISTÓRICO INMUEBLE EN EL PERÚ ENTRE 1821 Y 2014 ${ }^{\left({ }^{*}\right]}$
}

\author{
CULTURAL POLICIES AND STATE-NATION: \\ STATEMENTS OF THE HISTORICAL HERITAGE PROPERTY IN PERU \\ BETWEEN 1821 AND 2014
}

MILAGROS VALENZUELA SALDAÑA ${ }^{(* x)}$

Fecha de recepción: 01 de abril de 2015

Fecha de aprobación: 25 de abril de 2015

\section{RESUMEN}

El presente trabajo trata de las políticas culturales adoptadas por el Estado para la protección y conservación del patrimonio histórico inmueble, y cómo estas han evolucionado o no desde la formación del Perú como Estado-Nación hasta la actualidad. Asimismo, se describen los criterios que se utilizaron para la declaración de bienes inmuebles considerados hoy en día monumentos históricos que integran el Patrimonio Cultural de la Nación, cuya conservación y sostenibilidad en el tiempo está envuelta en una problemática debido al terrible estado en el que se encuentran, lo cual evidencia la carencia del Estado, que al contar con normas como la Ley № 28296, Ley General de Patrimonio Cultural, está coadyuvando más bien a la insostenibilidad de los inmuebles declarados como tal.

\section{PALABRAS CLAVE}

Patrimonio, monumentos, políticas culturales

\begin{abstract}
The present work analyzes the cultural policies adopted by the State for the protection and conservation of the built historic heritage and how they have evolved or not since the formation of Peru as a nation-state until the present. Additionally, it describes the criteria that have been used for the declarations of immovable property today considered historic monuments of the cultural heritage of the nation, whose conservation and sustainability is problematic due to the condition that they are in and the fact that the State regulations are too restrictive management instruments that contribute to the insustainability of such real estate in the long term.
\end{abstract}

\section{KEYWORDS}

Heritage, monuments, cultural policies

(*) El presente artículo forma parte del proyecto de tesis titulado "Gestión cultural del Patrimonio siniestrado: Caso del Teatro Municipal de Lima" iniciado el 2013 y elaborado para la obtención del título de Magister en Gestión del Patrimonio Cultural en la Universidad Nacional Mayor de San Marcos (UNMSM).

${ }^{* * *}$ Licenciada en Historia por la Universidad Nacional Mayor de San Marcos con estudios de Maestría en Gestión del Patrimonio Cultural y especialista en temas de educación patrimonial. Profesionalmente se ha desempeñado en diversas instituciones del Estado y actualmente labora como investigadora sobre temas de patrimonio edificado en el Ministerio de Cultura del Perú. 
¿Existen políticas culturales en el Perú? ¿De qué manera las políticas culturales del Estado peruano han sido o son significativas para la conservación del patrimonio histórico inmueble? Desde la formación del Perú como república, se han promulgado una serie de leyes, decretos, resoluciones, proyectos y realizaciones de tipo cultural. Estas políticas adoptadas por el Estado han sido básicamente lineamientos o principios instituidos por cada gobierno que ha presidido el país. Respecto a temas vinculados al patrimonio, estos lineamientos promovidos desde el Estado han girado casi siempre en torno a la protección del patrimonio arqueológico, y han tomado en cuenta solo el patrimonio histórico de la época colonial y republicana, ignorando por completo el patrimonio industrial o contemporáneo.

La preocupación por proteger el patrimonio histórico se inicia en el Perú en la década de los años 50 y 60, en parte, en el plano arquitectónico, debido a la desaparición de muchos ejemplares de testimonio de patrimonio edificado perteneciente al período posterior a la época prehispánica, cuya desaparición y deterioro se debió en muchos casos a los terremotos y sismos que se produjeron en el Perú a lo largo del siglo XX. Es a partir de esta problemática que se empezó a promover y a gestar proyectos para la evaluación y restauración de inmuebles, particularmente de aquellos considerados arquitectura religiosa, no solo con el fin de mantenerlos como espacios sagrados para el culto cristiano, sino también con fines de promoción turística.

Por otro lado, se percibe que la protección de todo el engranaje patrimonial y cultural del Perú, así como la propuesta de principios para desarrollar una política cultural desde el Estado, en muchos casos no han contado con documentos básicos que definan los lineamientos teóricos político-culturales a tomar en cuenta; como se mencionó anteriormente, estos solo se han sustentado en decretos, leyes y promulgaciones en muchos casos coyunturales, que más que establecer planes a largo plazo con miras a revertir las estructuras culturales de pueblos que muchas veces adolecen de taras históricas como el racismo, la exclusión y la indiferencia, se han ocupado sobre todo de resolver los problemas cotidianos tangibles, invirtiendo básicamente en infraestructura en vez de superestructura.

Siguiendo a Jorge Cornejo Polar, se entiende por políticas culturales a "un conjunto de objetivos que un Gobierno se propone alcanzar en el terreno de lo cultural y de las acciones que pone en juego para lograrlos" (Polar, 1987, pp. 59-65). Por lo tanto, se entiende que las políticas culturales tienen un fin específico desde el Estado; en otras palabras, están orientadas a formar al ciudadano de a pie, según los propios fines del Estado, promoviendo modelos de comportamiento social y cultural. En ese sentido, resulta interesante conocer la vinculación entre políticas culturales y patrimonio edificado.

El patrimonio cultural en su diversa gamas de manifestaciones, ya sean estas materiales o inmateriales, constituye una fuente de identidad, que en el caso del Perú implica reconocernos como una nación pluricultural, con un largo pasado prehispánico y coIonial que se revierte posteriormente en el sincretismo cultural que hoy conocemos, estudiamos y utilizamos para generar recursos para nuestras comunidades. Es crucial entender que el patrimonio cultural es una fuente de riqueza cultural y económica que puede generar bienestar económico para nuestras sociedades. Por esa razón, es importante que la intervención del Estado en bienes patrimoniales no esté supeditada a presiones políticas o denuncias mediáticas. Es preocupante observar que en las propuestas del Gobierno local y nacional no se expongan políticas culturales que incentiven un interés social y educativo por el patrimonio como herramienta importantísima para generar identidad, además de la conservación de nuestras ciudades históricas, cada vez más vandalizadas por las propias autoridades. 
devenir Vol. 2, N³, ENERO - JUNIO 2015, PP. 8-21 - ESTUDIOS I ISSN 2312-7570

UNIVERSIDAD NACIONAL DE INGENIERÍ, LIMA

\section{Periodificación de las Políticas Culturales en el Perú Referente al Patrimonio Cultural}

Para tener un mejor panorama de las políticas culturales en el Perú, conviene diferenciar las etapas en las que éstas han sido formuladas y puestas en práctica en el estado-nación. El primer período es el que se gesta desde el nacimiento de la República, comprende desde 1821 hasta aproximadamente 1929, y concluye con la creación del Patronato de Arqueología.

\section{Primer Período (1821-1929)}

Con el advenimiento de la República y la formación del Perú como Estado-nación, las políticas culturales de la élite criolla se caracterizaron por el rechazo a todo aquello que proviniera del legado colonial; se inicia más bien una gesta por recuperar lo prehispánico. En esa línea, una de las primeras políticas culturales de la naciente nación independiente fue la promulgación del general San Martín que dispuso la creación del Museo Nacional y la Biblioteca Nacional. Así, mediante el decreto del 8 de febrero de 1822, se creó la Biblioteca Nacional del Perú, con la finalidad de poner en circulación los valores intelectuales de la nación. Con respecto a la creación del Museo Nacional, este se comenzó a gestar a partir del decreto del 2 de abril del mismo año, en el que se establece la protección de las piezas prehispánicas, llamadas en ese entonces antigüedades:

Los monumentos que quedan de la antigüedad del Perú, son propiedad de la nación porque pertenecen a la gloria que deriva de ellos: las preciosidades de que abundan nuestros minerales, aunque puedan circular libremente en el país y mudar de dominio, pero el gobierno tiene derecho a prohibir su exportación cuando felizmente ha llegado el tiempo de aplicar a un uso nacional todo lo que nuestro suelo produzca de exquisito en los tres reinos de la naturaleza. Con dolor se han visto hasta aquí vender objetos inapreciables, y llevarse a donde es conocido su valor, privándonos de la ventaja de poseer lo nuestro. (Archivo digital del Congreso, 2015, sección normas internas)

Desde entonces existe una clara preocupación por proteger el legado prehispánico. En ese sentido, muchas de las primeras leyes que se emitieron desde los inicios de la República hasta bien entrado el siglo XX tuvieron la intención de proteger el patrimonio previo al del período colonial, y el énfasis fue que durante las primeras décadas del siglo XX el Estado legitimó al indigenismo, entendido como el culto a la monumentalidad del pasado incaico como su impronta oficial.

Entre estas normas se encuentra la Ley $\mathrm{N}^{\circ} 6634$, emitida bajo el asesoramiento de Julio C. Tello el 3 de junio de 1929, durante la presidencia de Augusto B. Leguía. Mediante dicha ley se creó el Patronato Nacional de Arqueología, entre cuyos artículos se señala que "Son de propiedad del Estado los monumentos históricos existentes en el territorio nacional anteriores a la época del Virreinato. Es inalienable e imprescriptible el derecho de la nación sobre dichos monumentos" (Archivo Digital del Congreso, 2015, sección normas internas)'.

Hasta ese momento lo que le preocupa al Estado era conservar el patrimonio precolombino, y la postura oficial se caracteriza por la legitimación de este pasado desde la intelectualidad y la academia, más no valora lo andino como cultura ancestral ni lo reivindica como modelo social a seguir.

1. El 9 de febrero de 1929 se emite la Ley $N^{\circ} 6523$, adicional a la Ley $N^{\circ} 6634$, la cual contempla entre sus consideraciones que el Patronato de Arqueología del Cusco se debe encargar de la conservación y vigilancia de los monumentos, obras de arte, pintura y demás de la época colonial que se encuentren en dicho departamento. 


\section{Segundo Período (1931-1939)}

Recién con el Decreto Ley № 7212 del 2 de julio de 1931 se dispone entre las funciones del Patronato Nacional de Arqueología la tarea de ejercer supervisión y control sobre los monumentos virreinales existentes en el territorio de la república, y establece entre sus consideraciones lo siguiente:

Que existiendo importantes restos de carácter histórico y artístico en toda la República, que constituyen verdaderos monumentos que el Estado debe controlar, es indispensable que el Patronato Arqueológico Nacional extienda su jurisdicción a estos últimos, como lo hace ya el Patronato del Departamento del Cuzco. (Archivo Digital de Congreso, 2015, sección normas internas)

La Ley № 6523 de 1929, adicional a la № 6634, restringía el registro de monumentos virreinales al departamento del Cusco. Recién en 1931 la Ley № 7212 amplia la protección de monumentos de la época virreinal a nivel nacional, y con el Reglamento de la Ley $\mathrm{N}^{\circ} 7212$, del 3 de enero de 1932, para lo cual se emite la Resolución Suprema № 78, se resuelve que los inmuebles, según su carácter histórico o artístico, pueden considerarse como monumentos nacionales, lo cual implica la categoría de intangible (Ravines, 1974, pp. 363-458).

Es importante mencionar que por primera vez se utiliza la denominación monumento nacional y se le da el carácter de intangibles para referirse a los bienes inmuebles, denominación que posteriormente cambiará por patrimonio cultural de la nación.

Durante estos años todavía no se consideraba de interés artístico o histórico a las edificaciones y bienes de origen republicano. ${ }^{2}$ Un año antes de la emisión de estas leyes, en el contexto internacional, se estaba llevando a cabo la Conferencia Internacional en Atenas en 1931, de cuyo espíritu nació la Carta de Atenas, documento internacional que establece los principios y criterios básicos para la restauración y conservación de monumentos históricos y artísticos, especialmente el planteamiento del vínculo indisoluble del bien con su historia y su lugar de ubicación.

\section{Tercer Período (1939-1972)}

La Ley $N^{\circ} 8853$, promulgada el 9 de marzo de 1939 por el entonces presidente Oscar R. Benavides, determina la creación del Consejo Nacional de Conservación y Restauración de lugares históricos, edificios, monumentos, muebles, joyas, pinturas, esculturas y, en general, de todo objeto de la época colonial que tenga valor histórico o artístico. Este Consejo se constituyó como el primer órgano oficial del Estado encargado de proteger y conservar los monumentos provenientes de la época colonial. Así, dentro de las facultades de este organismo se encontraba pronunciarse sobre los lugares y edificios que debían ser declarados monumentos.

Mediante estas leyes el Estado empieza a mostrar preocupación, además del legado arqueológico precolombino, por el patrimonio proveniente de la época colonial, a partir de lo cual también empieza a entender que forma parte de la riqueza cultural del país. Esta preocupación por lo colonial va de la mano con el pensamiento de algunos

\footnotetext{
2. Según el listado de bienes declarados Patrimonio Cultural de la Nación proporcionados para la presente investigación por el Ministerio de Cultura, los primeros monumentos declarados corresponden a edificaciones religiosas de la época virreinal, tal fue el caso de la Ley № 9193 y № 9194 de fecha 31 de octubre de 1940, mediante la cual se declara como monumento nacional a la lglesia de la Natividad de Cocharcas y la Capilla de la Merced respectivamente, ambas ubicadas en el departamento de Junín, provincia de Huancayo. Estas primeras declaraciones mantienen un espíritu estético arquitectónico, más que histórico. Es recién en 1941 cuando se empiezan hacer declaraciones por el valor histórico de la edificación: tal es el caso de la Ley $\mathrm{N}^{\circ}$ 9385, que declara como histórica la casa del sabio Antonio Raymondi en San Pedro de Lloc, y la Ley Nº 9441 que declara como tal, entre otras edificaciones, al Cuarto del Rescate en Cajamarca.
} 
de los intelectuales de esa época, como el sacerdote jesuita Rubén Vargas Ugarte y el arquitecto e investigador Emilio Harth Terre. Además, los estudios históricos también enfatizan ese período: historiadores como Raúl Porras Barrenechea y Guillermo Lohmann Villena dedicaron muchos de sus escritos a describir y analizar el pasado colonial. No resulta sorprendente entonces la nueva preocupación por proteger las edificaciones religiosas, las pinturas y las esculturas de dicho periodo.

El Consejo Nacional de Conservación y Restauración se encargó de promover una serie de leyes orientadas a proteger individualmente iglesias y algunas casas aisladas en lugares de significación histórica. Además, la gestión de este organismo se dedicó no solo a la conservación y protección de bienes, sino que también realizó investigaciones de tipo histórico-arquitectónico sobre edificaciones religiosas ${ }^{3}$; incluso se podría afirmar que la presidencia del padre Rubén Vargas Ugarte en el Consejo Nacional de Conservación y Restauración tuvo entre sus lineamientos promover una neo-evangelización en el Perú, promoviendo desde lo oficial la conservación y declaración de monumentos coloniales de tipo religioso.

En 1950, a raíz del terremoto que asoló la ciudad del Cusco, se creó la Junta de Reconstrucción y Fomento Industrial del Cusco, según Decreto Supremo de enero de 1952. A partir de esta junta, diversas instituciones internacionales como la Organización de las Naciones Unidas para la Educación, la Ciencia y la Cultura (UNESCO), y países como España empezaron a intervenir en la conservación de monumentos en el Perú. Asimismo, debido a los terremotos que asolaron buena parte del patrimonio monumental en Cusco, Arequipa y Puno, el Estado creó el Plan COPESCO, organismo encargado de diseñar las políticas de inversión en infraestructura con la intención de fomentar el turismo. Es preciso señalar que en esa época el turismo empezó a ser promovido como gestor de recursos para la economía financiera del país, por ello el interés del Estado en su promoción. Sin embargo, como bien lo señala Stastny (1986), este tipo de enfoque suele implicar que se piense menos en la naturaleza del objeto histórico y en la carga conceptual que este conlleva, y se tienda a pasar por alto que el propósito original de aquellas tareas es incorporar el monumento a la corriente viva de la tradición cultural de un pueblo, que se trata de comprenderlo mejor, de iluminar con nuevos datos su pasado y su valor simbólico, y también de recuperar su integridad física y, así, la belleza de su unidad perdida a fin de que se convierta en una fuente de enriquecimiento interior para los individuos que se aproximan a él, un componente vivo, útil para la sociedad.

Durante los años 60 se dio mayor énfasis a la preservación de monumentos, tanto arqueológicos como coloniales y republicanos, a nivel nacional. En 1961 se aprobó mediante el Decreto Supremo № 19, el reglamento presentado por el Consejo Nacional de Monumentos Históricos y Artísticos, que constaba de 7 capítulos y 38 artículos, para que fuera incluido dentro del Reglamento de Construcciones Municipales. La importancia de dicho reglamento radica en que a través de él se reglamenta la conservación y restauración en las construcciones civiles (Ramírez, 2005). Desde esa mirada ya proteccionista y la preocupación por el crecimiento urbano de Lima ${ }^{4}$, la Municipalidad Metropolitana de Lima creó en 1962 la Junta Deliberante Metropolitana de Monumentos Históricos, Artísticos y Arqueológicos de Lima, presidida por Juan Manuel Ugarte Elespuru, quien junto a un equipo técnico de arqueólogos, ar-

\footnotetext{
3. Entre las publicaciones del Consejo Nacional de Conservación restauración se encuentra los estudios Santuario y beaterio de Nuestra Señora del Patrocinio, Exposición del libro y manuscrito colonial, La Sacristía del Templo de San Agustín de Lima, Exposición de cuadros y objetos de arte virreinal. Para mayor información ver Memorias del Consejo Nacional de Conservación y Restauración de Monumentos Históricos 1959, 1960-1961.

4. El crecimiento urbano de Lima trajo consigo que se ensancharan y se abrieran nueva avenidas en el Centro Histórico de Lima. Para ello se demolieron algunas edificaciones, como la iglesia Santa Teresa para abrir la avenida Abancay.
} 


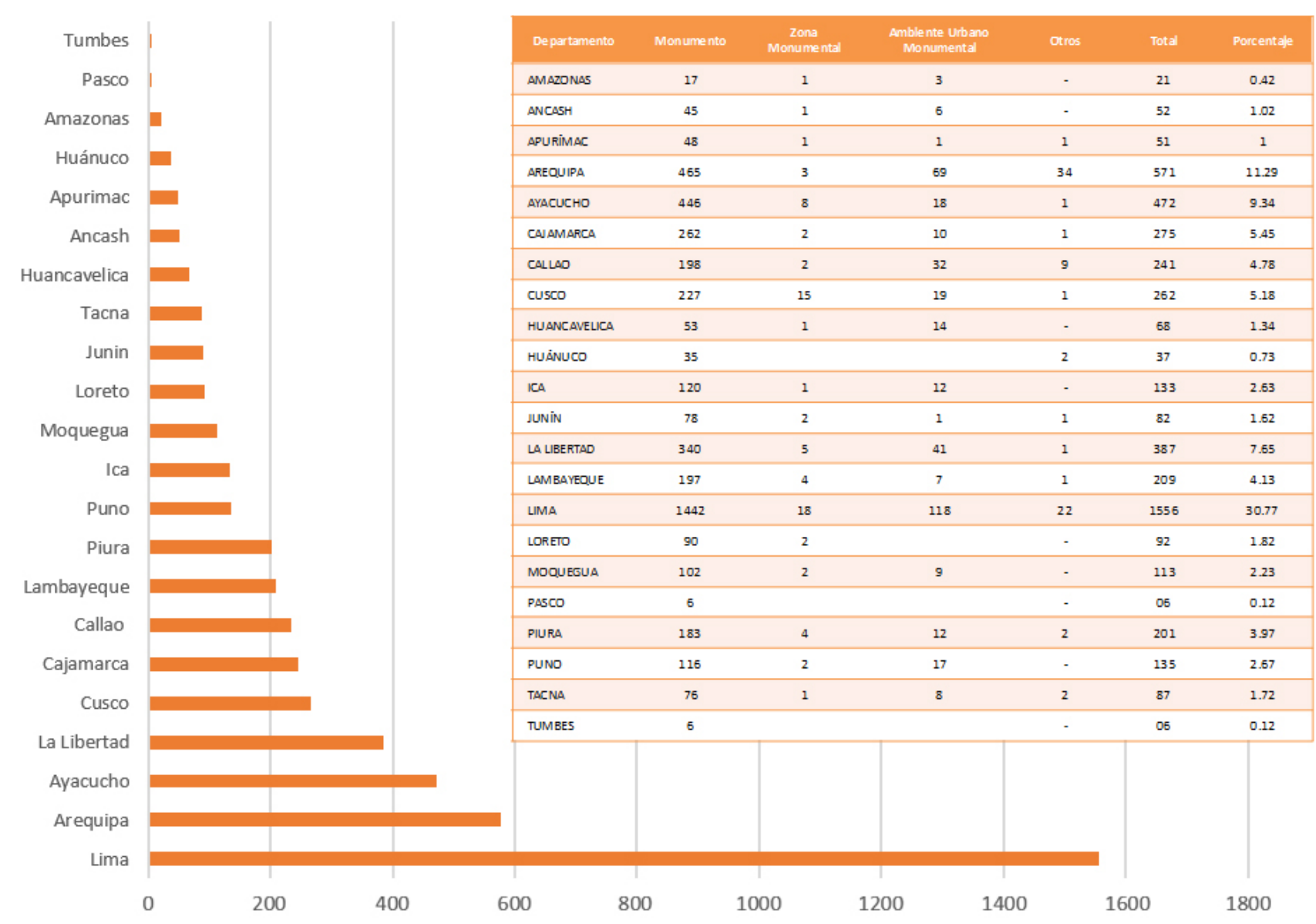

- Patrimonio Inmueble

quitectos, historiadores y abogados elaboró un estudio de 6 tomos durante los años 1962 y $1963^{5}$. Este estudio incluía informes sobres los monumentos arqueológicos, coloniales y republicanos de Lima, además de estudios legales sobre los monumentos y los organismos tutelares. En el equipo técnico de esta Junta se encontraban los arquitectos Héctor Velarde, Rafael Marquina, José García Bryce y Víctor Pimentel'.

En esta misma década hubo un intento del Estado por consolidar la cultura nacional en todas sus manifestaciones: el 24 de agosto de 1962, mediante el Decreto Supremo № 48, se crea la Comisión Nacional de Cultura, la cual se refuerza con el Decreto Ley No
Gráfico 1. Monumentos declarados Patrimonio Cultural de la Nación a nivel nacional.

Fuente. Dirección de Patrimonio Histórico Inmueble del Ministerio de Cultura, 2015.

5. Junta Deliberante Metropolitana de Lima. El informe publicado por esta comisión contiene un inventario sobre los monumentos históricos de Lima. En dicho inventario se puede encontrar información histórica sobre los inmuebles de Lima Metropolitana, así como el grado de conservación que se le debía dar a cada monumento. Se puede decir que este es el primer registro científico sobre monumentos, ya que las declaraciones como patrimonio cultural de la nación de los monumentos que se hicieron desde 1970 hacia adelante no cuentan con un expediente de declaración. Las declaraciones tendían a ser instrumentos legales, por los que se declaraban más de 200 inmuebles a nivel nacional, pero que solo citaban al monumento y su ubicación geográfica, sin llegar hacer un estudio arquitectónico e histórico de cada inmueble.

6. El arquitecto Víctor Pimentel representó al Perú en el II Congreso Internacional de Arquitectos y Técnicos en Monumentos Históricos-CIAM llevado a cabo en Venecia en 1964. De dicha conferencia nació la Carta de Venecia, documento internacional que el Perú firmó, del cual se desprenden los principios teóricos sobre la restauración y conservación de monumentos, en el cual se enfatiza la autenticidad y valor excepcional de estos. 
14479 del 10 de junio de 1963. A la luz de esta Comisión se creó la Casa de la Cultura, ente que absorbió todas las organizaciones estatales del sector cultura. Uno de sus más destacados directores fue el escritor José María Arguedas, quien buscó potenciar todas las manifestaciones culturales del país, en especial aquellas vinculadas al arte popular. La Casa de la Cultura del Perú fue disuelta mediante el Decreto Ley № 18799, el 9 de marzo de 1971, al crearse el Instituto Nacional de Cultura (Coloma, 2001), organismo público descentralizado del sector educación, que entre sus funciones tenía:

...promover, de acuerdo a la política del Sector, las manifestaciones culturales que signifiquen la formación de los valores propios del país, contribuyendo a que el pueblo peruano tome conciencia de su historia, situación y destino. Le corresponde, además, la conservación y protección del patrimonio arqueológico, histórico, artístico y cultural de la Nación, así como la protección de la propiedad intelectual. (Decreto Ley № 18799, 1971, pp. 1-3)

\section{Cuarto Período (1972-2010)}

En este período, es indiscutible el aporte de Jorge Cornejo Polar, notable crítico literario y experto en políticas culturales, director, además, del otrora Instituto Nacional de Cultura (INC) durante el gobierno de las Fuerzas Armadas. Se puede afirmar que es a partir de 1972 que se empieza a reflexionar académicamente sobre las políticas culturales del Estado-Nación. Cornejo Polar (1993) afirma que las políticas culturales son el conjunto de normas constitucionales y legales que pone en vigencia o aplica un gobierno en el campo de la cultura. Plantea que para que exista una política cultural en el sentido propio del término, es necesario que exista un proyecto definido y coherente en el ámbito cultural del país, que comprenda fines a largo plazo, objetivos a mediano y corto plazo, y un conjunto de medios legales, financieros, organizativos, humanos, de infraestructura y equipamiento que permitan el logro de tales fines y objetivos.

Es interesante el análisis que se puede hacer de la perspectiva estatal acerca de las políticas culturales, las cuales se encuentran plasmadas en el documento titulado "Bases para la política cultural de la revolución peruana", publicado en 1975 en la revista Runa, publicación oficial del INC. El documento, elaborado por el Consejo General de Cultura, el principal órgano consultivo del INC, organismo creado durante el gobierno militar de Juan Velasco Alvarado, sentaba las bases políticas e ideológicas para el Estado en materia cultural.

El texto empieza con una definición de cultura, señalando a esta como "el conjunto de valores -tanto materiales como simbólicos- que incentivan, norman y regulan internamente las relaciones cotidianas de las personas y grupos sociales dentro de la comunidad" (Polar, 1975, pp. 1-5). Sigue un análisis de la realidad cultural peruana, en el que se afirma que nuestro imaginario cultural se vio interrumpido por el proceso de la conquista, período de dominación que se afianzó en la época colonial, dejándonos estructurados mentalmente con una cultura alienante. Para revertir ese proceso de dominación y alienación, el documento propone la construcción de un nuevo hombre peruano dentro de una sociedad socialista, democrática y particionista. Si se considera que toda política cultural se caracteriza por sus fundamentos ideológicos, definitivamente este documento constituyó una iniciativa por cambiar y romper con los paradigmas culturales de los peruanos. El documento se enfoca y dirige a cambiar las estructuras mentales y los hábitos alienantes del hombre peruano.

La lectura de este documento es muy alentadora, pues contempla el pluralismo y la diversidad como eje cultural, además de sustentar los fundamentos teóricos de las políticas culturales del Gobierno Revolucionario de las Fuerzas Armadas. Lastimosamente este documento no prosperó; se convirtió solo en una declaración de intenciones. 
La labor del INC promovió la protección de los monumentos a gran escala. Ya entonces se empezó a considerar el patrimonio monumental como bien integrante de la nación. Así, el Decreto Ley № 19033, de fecha 16 de noviembre de 1971, establece en su Artículo $1^{\circ}$ que los bienes inmuebles del patrimonio monumental de la nación corresponden a las épocas preincaica, incaica, colonial y republicana, y en su Artículo $2^{\circ}$ precisa que los monumentos de las épocas pre-incaica e incaica son propiedad del Estado y por tanto inalienables e imprescriptibles, pues su carácter de monumento es implícito y no necesitan ser declarados expresamente. Respecto a los inmuebles de la época colonial y republicana, el Artículo $3^{\circ}$ señala que, por sus méritos arquitectónicos estéticos, urbanísticos, históricos o documentales, deben ser conservados y puestos en valor, aunque sí requieren ser declarados expresamente como monumentos por Resolución Suprema refrendada por el Ministerio de Educación, y deben inscribirse en el Registro de la Propiedad Inmueble.

En este período se inician las declaraciones en masa de patrimonio civil y doméstico, en torno a lo que se percibe uno de los paradigmas del Estado de aquel entonces: el patrimonio como bien común, ya que de alguna manera, al declararse un monumento del tipo doméstico, se estaba siguiendo la práctica de expropiar el bien inmueble en beneficio del bien común, bajo la idea de difundir y proteger los valores culturales e históricos de este tipo de edificaciones.

\section{Quinto Período (2010 hasta la actualidad)}

Mediante la Ley № 29565 del año 2010 se creó el Ministerio de Cultura, y a través del Decreto Supremo № 001-2010-MC se aprobó la fusión del Ministerio de Cultura, bajo la modalidad de absorción, con diversas entidades entre las cuales se encontraba el INC, cuyas funciones concluyeron el 30 de setiembre de 2010. A pesar de que el Ministerio de Cultura tiene presencia a nivel del Poder Ejecutivo, aún no se percibe un interés real por establecer políticas culturales de largo aliento, o un proyecto nacional que promueva cambios en el paradigma o fomente el modelo del ciudadano que se quiere formar. Además de ello, aún el Ministerio de Cultura no ha emitido una nueva ley en torno al Patrimonio Cultural de la Nación; este sigue normado bajo los alcances de la Ley № 28296, Ley General de Patrimonio Cultural de la Nación, cuyo principio fundamental dice ser la defensa, protección y promoción de los bienes que forman parte del patrimonio cultural en el Perú. Pero, ies suficiente esta ley para proteger el patrimonio edificado arquitectónico en el Perú? La respuesta es, obviamente, no. La Ley № 28296 es muy general y presenta enormes vacíos que vulneran la conservación de los bienes en su totalidad.

Dichas leyes clasifican los bienes que integran el Patrimonio Cultural de la Nación como bienes materiales e inmateriales, y a los primeros como muebles o inmuebles. Lo inmueble comprende, según la ley, lo siguiente: "de manera no limitativa, los edificios, obras de infraestructura, ambientes y conjuntos monumentales, centros históricos y demás construcciones, o evidencias materiales resultantes de la vida y actividad humana urbanos y/o rurales, aunque estén constituidos por bienes de diversa antigüedad o destino y tengan valor arqueológico, arquitectónico, histórico, religioso, etnológico, artístico, antropológico, paleontológico, tradicional, científico o tecnológico, su entorno paisajístico y los sumergidos en espacios acuáticos del territorio nacional" (INC, 2009, p. 9).

Es preciso indicar que la Ley $\mathrm{N}^{\circ} 28296$, aunque enfatiza los valores que poseen los bienes culturales en el Perú, no indica cómo se debe proceder para preservarlos o protegerlos, ya sea del paso del tiempo, la mano del hombre o los desastres naturales que suelen ser comunes en el Perú, tales como sismos, terremotos, fenómenos climáticos o incendios. Esta carencia, sumada a otros factores, es una de las principales causas de deterioro de los edificios históricos. 
Según Ríos Vizcarra (2011), entre los factores ambientales y naturales que inciden en el deterioro de los monumentos se encuentran los siguientes: factores naturales como los sismos y tsunamis, muy frecuentes en el Perú, debido a su ubicación en la costa occidental de Sudamérica; los factores climáticos, ya que todos los materiales se degradan con el paso del tiempo debido a una serie de fenómenos atmosféricos que definen el clima, tales como la temperatura, la presión, la humedad, las precipitaciones (lluvia, nieve, rocío, niebla, etc.); y la contaminación atmosférica, que se debe básicamente a las emisiones del parque automotor, el sector industrial y la industria gráfica.

La ignorancia y el vandalismo son prueba latente de la inexistencia de una educación patrimonial que se promueva desde la educación básica regular, y del desconocimiento del valor que una edificación histórica puede tener. De hecho, las municipalidades son uno de los primeros agentes de destrucción, ya que con afanes protagónicos intervienen espacios públicos significativos o monumentos arquitectónicos y, en lugar de recuperarlos, los destruyen con el fin de dejar su propia impronta mediática (Ríos, 2011). También existe un alarmante desconocimiento de las técnicas y procedimientos necesarios para su tratamiento y conservación, lo cual puede causar daños irreparables en el patrimonio edificado.

Otro factor que actualmente contribuye a la destrucción del patrimonio es la falsa idea de modernidad asentada en la población y en las mismas autoridades locales. Muchas edificaciones antiguas, que datan incluso del periodo colonial, han sido demolidas para dar paso a edificios de 10 o 20 pisos, en algunos casos rascacielos que afectan el perfil urbano de la ciudad. Como consecuencia del boom de la construcción, solo en Lima, entre el año 2010 y 2013, numerosas haciendas y casas de los primeros años de la era republicana fueron demolidas para poner en su lugar centros comerciales, edificios multifamiliares o playas de estacionamiento, edificaciones que en muchos casos no representan ningún atractivo urbano o paisajístico. Todo esto denota el desconocimiento de la historia de la ciudad por parte de las autoridades, quienes evidencian poca o nula importancia por mantener estándares de calidad en el paisaje urbano de la ciudad.

Desde 2010 hasta la actualidad se han declarado pocos monumentos; ya casi no se declara nuevos monumentos históricos, en parte debido en parte a que la gestión del trámite de declaración requiere de la aprobación del propietario del inmueble.

\section{Problemática de la Protección del Patrimonio Cultural en el Perú}

La riqueza patrimonial que posee el Perú es tanto cultural como natural; ambos elementos forman nuestro legado cultural. El Estado peruano protege este legado a través de instancias como el Ministerio de Cultura, el Ministerio del Ambiente, el Ministerio de Comercio Exterior y Turismo, el Ministerio de Relaciones Exteriores, el Instituto Nacional de la Competencia y la Propiedad Intelectual, además de otros organismos que tienen injerencia a nivel distrital, como las municipalidades; sin embargo, el organismo rector en temas de competencias de la protección del patrimonio (sea este material o inmaterial) es el Ministerio de Cultura, el cual ha enfocado la mayoría de sus políticas culturales a la protección del patrimonio arqueológico, parcialmente debido a que este pertenece al Estado, por lo que puede intervenir e incluso financiar su recuperación a través de sistemas como el Sistema Nacional de Inversión Pública (SNIP). A diferencia del arqueológico, el patrimonio arquitectónico puede ser de propiedad privada y no puede contar con presupuesto del Estado para su recuperación, a menos de que se trate de bienes religiosos como templos o iglesias.

La UNESCO (1986) plantea que la conservación y protección de los bienes culturales requieren la elaboración de un plan de manejo específico que analice y contemple su valor científico, social y espiritual, que visualice una unidad de gestión e incluya un 
esquema u organigrama que asegure el mantenimiento diario del bien, tanto como las necesidades de conservación a largo plazo, además de las medidas esenciales para su exhibición al público y su protección.

En el año 2004 se promulgó la Ley № 28296, Ley General del Patrimonio Cultural de la Nación, que incluye la siguiente definición:

Se entiende por bien integrante del Patrimonio Cultural de la Nación toda manifestación del quehacer humano -material o inmaterial- que por su importancia, valor y significado paleontológico, arqueológico, arquitectónico, histórico, artístico, militar, social, antropológico, tradicional, religioso, etnológico, científico, tecnológico o intelectual sea expresamente declarado como tal o sobre el que exista la presunción legal de serlo. Dichos bienes tienen la condición de propiedad pública o privada con las limitaciones que establece la presente ley. (INC, 2004, p. 7)

El Ministerio de Cultura del Perú, a través de sus diferentes Direcciones, clasifica el patrimonio cultural inmueble como patrimonio arqueológico o patrimonio histórico, y aplica la segunda categoría a todo inmueble proveniente de la época colonial y republicana. Así, la Dirección de Patrimonio Histórico Inmueble, el ente encargado de velar por la conservación del patrimonio arquitectónico en el Perú, tipifica el patrimonio como arquitectura religiosa, arquitectura civil doméstica, arquitectura civil pública, arquitectura militar, ambientes urbanos monumentales y zonas monumentales.

\section{Arquitectura Religiosa}

Símbolo del cristianismo en América, la construcción de edificaciones religiosas fue parte integral de la política evangelizadora de España. Esta tipología arquitectónica está referida a todas aquellas iglesias, templos, santuarios religiosos o conventos construidos durante la época colonial que sirvieron como lugares en los que las diferentes órdenes sacerdotales que llegaron al Perú impartían los sacramentos a los feligreses en general.

\section{Arquitectura Civil Doméstica}

Se considera Arquitectura Civil Doméstica a las edificaciones del tipo casa-habitación. El criterio para declarar este tipo de edificaciones es el valor arquitectónico que poseen (colonial, republicano, o de algún estilo particular de una determinada época) y, además, su valor histórico, es decir, su significación cultural (por ejemplo, si personajes importantes la habitaron). En el Perú la mayoría de casas declaradas monumento integrante del Patrimonio Cultural de la Nación son de propiedad privada. El Estado, al declararlas como tal, cumple la función de protegerlas, pero esta protección no involucra un plan de gestión para su conservación a largo plazo, lo cual deja, de manera autoritaria, todo el financiamiento a los propietarios.

\section{Arquitectura Civil Pública}

La Arquitectura Civil Pública hace referencia a los edificios emblemáticos construidos por el Estado. En esta tipología se encuentran, por ejemplo, el Palacio de Gobierno, el Teatro Municipal y el Palacio Municipal.

\section{Arquitectura Militar}

El rubro de Arquitectura Militar comprende las fortificaciones y baluartes construidos en zonas estratégicas para la defensa de la ciudad, tal como el Real Felipe, ubicado en el Callao.

\section{Ambientes Urbanos Monumentales}

Los Ambientes Urbanos Monumentales son aquellas plazas y calles que, tomadas como unidades individuales, se caracterizan por su belleza arquitectónica-urbanística y la unidad de su edificación, o por conservar su carácter tradicional, lo que les confiere valor documental. La mayoría de los ambientes urbanos considerados monumentales datan de la época colonial y republicana, pocos pertenecen al presente siglo (Velarde y Pimentel, 1962-1963). 
devenir Vol. 2, N³, ENERO - JUNIO 2015, PP. 8-21 - ESTUDIOS I ISSN 2312-7570

UNIVERSIDAD NACIONAL DE INGENIERÍ, LIMA

Gráfico 2. Monumentos declarados Patrimonio Cultural de la Nación por décadas.

Fuente. Dirección de Patrimonio Histórico Inmueble del Ministerio de Cultura, 2015

\section{DECLARACIONES PATRIMONIO INMUEBLE}

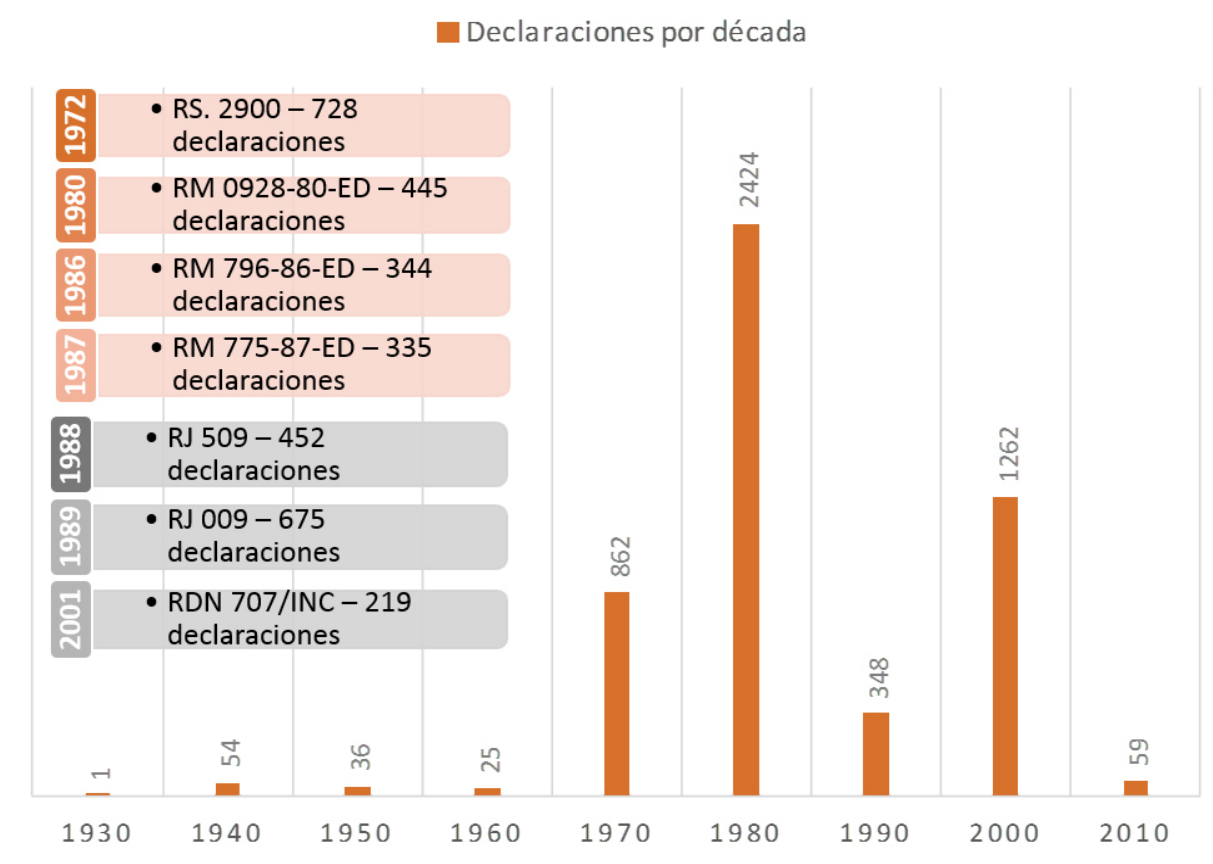

\section{Zonas Monumentales}

Las Zonas Monumentales son sectores urbanos o rurales más o menos amplios cuyo trazo o conformación original deben mantenerse, pues en ellos existen conjuntos de monumentos y ambientes urbanos valiosos que deben ser preservados. Los límites de las Zonas Monumentales se determinan en la ciudad mediante las vías que las circundan (Velarde y Pimentel, 1962-1963).

\section{Declaración de Bienes Integrantes del Patrimonio Cultural de la Nación}

Los criterios que se toman en cuenta para declarar una edificación como patrimonio cultural de la nación son básicamente el valor histórico, artístico, arquitectónico y simbólico, además del valor documental que puede poseer el bien; estos constituyen importantes testimonios de la evolución arquitectónica de las ciudades a través de su devenir histórico (ver Gráfico 3).

Pese a que se reconoce la importancia de declarar monumentos históricos, como afirma el arquitecto urbanista Wiley Ludeña Urquizo (2008), estas declaraciones han tenido criterios sesgados, propios de una corriente de arquitectos que entendía por monumentos históricos aquellos inmuebles que representan el poder político, religioso y social (palacios, iglesias y conventos, y casonas), visión decimonónica del patrimonio que posteriormente se convertiría en la postura oficial del Estado hasta la actualidad.

Es preciso señalar que las declaraciones en torno al Patrimonio Cultural de la Nación en lo que respecta a edificaciones coloniales o republicanas que se han hecho en el Perú, no contaban inicialmente con un expediente técnico de declaración; es decir, cuando el Estado declaraba una edificación, no se contaba precisamente con una ficha técnica de datos básicos de información histórica y gráfica del inmueble, ni tampoco con un plano del emplazamiento de esta. Una gran cantidad de inmuebles declarados como Patrimonio Cultural de la Nación corresponden al año 1972 (ver 


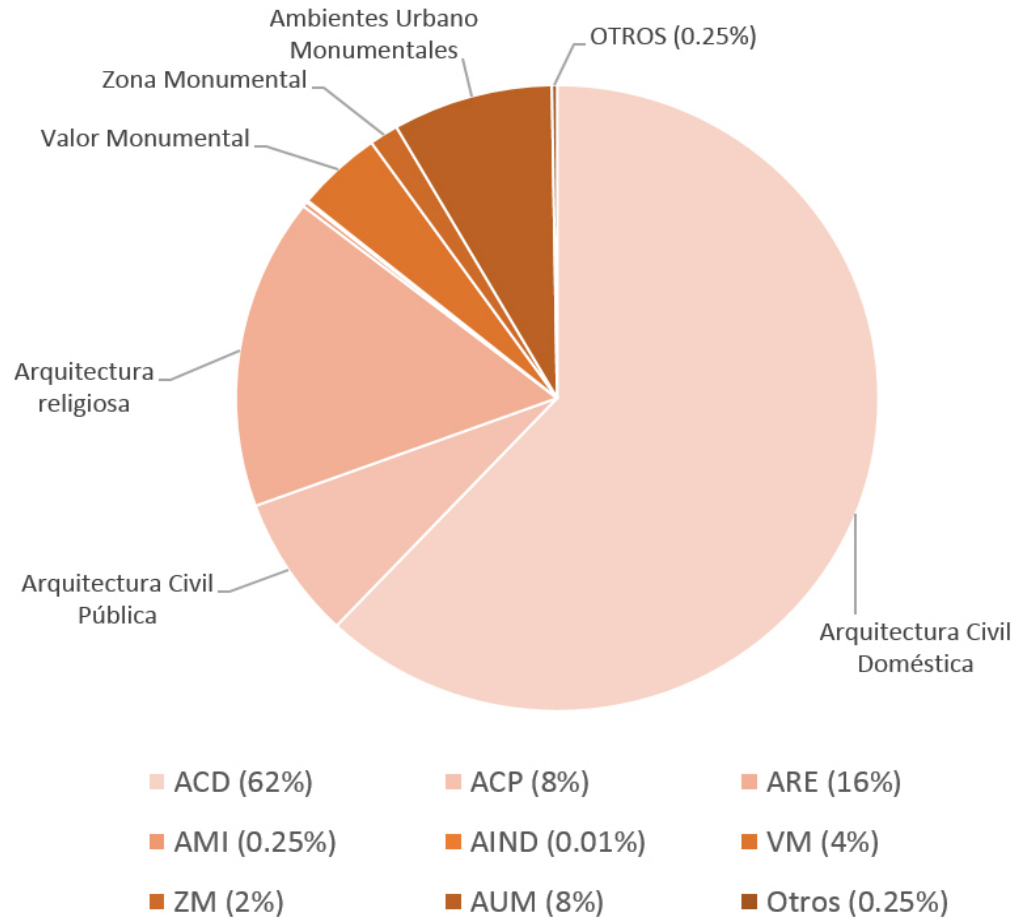

Gráfico 2), cuando el Ministerio de Educación emitió la Resolución Suprema № 2900, tras lo cual se declararon más de 700 inmuebles a nivel nacional. Si bien esta resolución protegía una gran cantidad de inmuebles, esta se reducía a la elaboración de un simple listado en el que se consignaba la denominación del inmueble y la dirección, la cual en muchos de los casos no correspondía a todo el inmueble matriz, sino solo a parte de él.

Se ha observado que algunas declaraciones de monumentos, sobre todo las que se hicieron posteriormente a 1972, no han sido sostenibles, ya que muchos de esos monumentos declarados como patrimonio cultural de la nación en la actualidad se encuentran derruidos, sus muros y estructuras en peligro de colapso. En estos casos, si el inmueble es de propiedad privada, el Ministerio de Cultura no puede intervenir económicamente, solo puede dar pautas técnicas sobre cómo restaurarlos o conservarlos.

A partir del año 2000 se ha encontrado declaraciones de inmuebles de valor histórico o arquitectónico que cuentan con un expediente de declaratoria, el cual incluye un estudio histórico, y un estudio arquitectónico de plantas y volumetría del bien, además de la existencia de documentos fehacientes que acreditan la fábrica matriz del inmueble.

Según la Dirección de Patrimonio Histórico Inmueble del Ministerio de Cultura, actualmente el Perú cuenta con 5167 monumentos declarados como bienes integrantes del patrimonio cultural de la nación (ver Gráfico 1), de los cuales 1584 están ubicados en Lima Metropolitana y 684 específicamente en el Centro Histórico, entre Arquitectura Civil Pública, Doméstica, Religiosa, Ambientes Urbanos y Zonas Monumentales.

La declaración de monumentos integrantes del Patrimonio Cultural de la Nación es a partir del mes de octubre de 2010, función del viceministerio de Patrimonio Cultural e Industrias Culturales del Ministerio de Cultura.
Gráfico 3. Clasificación de monumentos declarados Patrinomio Cultural de la Nación por tipo.

Fuente. Dirección de Patrimonio Histórico Inmueble del Ministerio de Cultura, 2015. 


\section{Conclusiones}

Desde la formación del Perú como república se han emitido una serie de normas orientadas a garantizar la protección del patrimonio cultural en su infinita gama de manifestaciones culturales, acervos documentales, bibliográficos, arqueológicos, coloniales y naturales, incluso inmateriales. Originalmente el Estado promovió la protección del patrimonio arqueológico a través de instancias como el Patronato de Arqueología, lo cual evidencia una clara intención de promover la valoración de la cultura prehispánica desde las tribunas oficiales.

Posteriormente, en la década de los años 40 , tras la afectación arquitectónica y estructural de emblemáticas edificaciones religiosas debido a diversos sismos ocurridos en ciudades como Cusco y Arequipa, se puso en marcha el Plan COPESCO para su recuperación. Ello evidenció una clara tendencia oficial hacia la preservación de inmuebles vinculados a lo religioso y lo cívico. Esta iniciativa promovió la promulgación de una serie de leyes de protección del patrimonio arquitectónico a través de dispositivos legales que declaraban a estas edificaciones como monumentos históricos. Sin embargo, si bien existía un interés por preservar este tipo de edificaciones, se limitó a un nombramiento, que no implicó la consideración del estado del deterioro y el desgaste generado por el paso del tiempo, las fuerzas naturales o la intervención humana.

Hoy en día muchas edificaciones declaradas como monumento se encuentran terriblemente destruidas y desgastadas, en preocupante estado de conservación, y esa clasificación no tiene utilidad en su recuperación. En ese sentido, considero que las declaraciones como monumento que se han hecho de inmuebles coloniales y republicanos por parte del Estado son en gran parte insostenibles, ya que en la actualidad muchos de ellos se encuentran en ruinas. Por ejemplo, en el Centro Histórico de Lima, particularmente en Barrios Altos, se puede apreciar muchos inmuebles de notable valor arquitectónico e histórico, típicas casas solariegas que se encuentran emplazadas en una trama urbana colonial, pero que cada día están perdiendo valor sin que el Estado pueda intervenir, debido a su condición de propiedad privada.

Por lo tanto, corresponde al Estado crear instrumentos de gestión y leyes que permitan la recuperación de dichos monumentos, además de su puesta en valor y uso, de forma que sea posible crear lazos de identidad entre estos bienes inmuebles y la comunidad. Un posible punto de partida sería la emisión de leyes menos restrictivas y más constructivas, que de alguna manera, económicamente, beneficien a los propietarios de estos inmuebles o, a través de un esfuerzo conjunto entre el Gobierno local y central, la creación de dispositivos legales que protejan a estos inmuebles en conjunto, y no como elementos aislados, ya que muchos de estos forman parte de una trama urbana que debe respetarse y conservarse.

Por otro lado, es necesario que las declaraciones respecto de los monumentos históricos considerados patrimonio cultural de la nación sean acompañados de un plan de gestión que indique cómo conservarlos en el tiempo, cómo protegerlos de los desastres naturales o del mismo ser humano. Asimismo, el Estado debe entender que el Perú es un país mestizo con una rica herencia prehispánica, pero también un país con un pasado colonial; es a partir de esa diversidad que se debe entender el patrimonio, de forma que pueda perdurar para las generaciones futuras. Además, es importantísimo que en las escuelas se incluya la educación patrimonial como herramienta base para evitar el desinterés o el desconocimiento del patrimonio edificado en su conjunto, tanto colonial y republicano, como contemporáneo. 


\section{Referencias}

Avalos, R. \& Ravines, R. (1974). Las antigüedades peruanas y su protección legal. Revista del Museo Nacional. Volumen (XL) 363-458.

Archivo Digital del Congreso. (2015). Sección normas internas. Recuperado el 25 de febrero de 2015. http://www.leyes.congreso.gob.pe/

Coloma, C. (2001). ¿Una casa de la cultura? El Comercio, 14.

Cornejo, J. (1987). Cuadernos de Historia III. Estado y cultura en el Perú republicano. Lima, Perú: Editorial Departamento Académico de Ciencias Humanas de la Universidad de Lima.

Cornejo, J. (1993) Políticas culturales y políticas de comunicación en el Perú (1895-1990) (Cuaderno CICOSUL 14). Lima, Perú: Facultad de Ciencias de la Comunicación de la Universidad de Lima.

Cortes, G. (Ed.). (2006). Políticas culturales: Ensayos críticos. Lima, Perú: Instituto de Estudios Peruanos.

Hayakawa, J. (2010). Restauración en Lima. Pasos y contrapasos. Lima, Perú: Universidad San Martín de Porres.

Instituto Nacional de Cultura. (1977). Bases para la política cultural de la revolución peruana. Runa. (Número 1).

Ludeña, W. (2008). Patrimonio Industrial en el Perú del Siglo XX: ¿Exotismo Cultural o Memoria Sin Memoria? Apuntes. Recuperado de http://www.scielo.org.co/pdf/apun/v21n1/ v21n1a07.pdf

Ministerio de Cultura. (2014). Marco legal de protección del patrimonio. Recuperado de https://www.cultura.gob.pe/sites/default/files/archivosadjuntos/2015/03/ley28296folleto2014-ok.pdf

Ramírez, F. (2005). Legislación patrimonio edificado. Recuperado de http://es.scribd.com/ doc/13648300/Legislacion-1\#scribd

Ríos, G. (2011). Manual para la valoración y conservación del patrimonio arquitectónico de Arequipa: Orientaciones básicas para el mantenimiento de la arquitectura doméstica. Arequipa, Perú: Universidad Católica Santa María.

Stastny, F. (1986). La preservación del arte colonial en el Perú. Patrimonio Cultural: Balance y Perspectivas.155-290. Lima: FOMCIENCIAS.

Organización de las Naciones Unidas para la Educación, la Ciencia y la Cultura (UNESCO). (2003). La gestión, clave para la preservación y sostenibilidad del patrimonio cultural. Lima, Perú: Autor.

Velarde, H. \& Pimentel, V. (1962-1963). Informe de la Comisión de Calificación de Monumentos Coloniales y Republicanos. Manuscrito sin publicar. Junta Deliberante Metropolitana de Monumentos Históricos, Artísticos y lugares arqueológicos de Lima, Lima, Perú. 